REFERLNCES

ClAUS, E. P., \& TYLER, V. $\mathrm{l} .$, JR Pharmacognosy: (5 th ed.) Philadelphia: Lea \& Febiger, 1965.

INGRAM, A. L. Morning glory seed reaction. Journal of the American Medical Association, $1964,190,1133-1134$.
MONTGOMERY. k. C. The rok of the exploratory drive in learning. Joumal of Comparative \& Physiological Psy' chology, 1954 47,60 .

RICE, W. B., \& GENEST, K. Acute toxicity of extracts of morning-glory seeds in mice. Nature, $1965,207,302$.

\title{
Aversive stimulation and reversal learning
}

\begin{abstract}
JOHN J. OMALLEY' and JAMES L. BRUNING, Ohio Universitn, Athens, Ohio 4.5701
\end{abstract}

Albino rats were initially trained to make a black white discrimination to escape from high (.8 $\mathrm{mA}$ ) or low shock (.3 $\mathrm{mA})$. Reversal training was then begun either immediatel. after $S$ s reached an 8 out of 10 performance criterion or after 95 overtraining trials. Shock level did not affect performance in original training. There were no differences in trials-to-reversal criterion due to shock level or amount of prereversal training. However, as in appetitive situations, overtrained Ss made more consicutive perseverative errors following cue reversal, and showed less tendency to respond positionally during the first 24 reversal trials. Shock level did not affect perseveration or position responding.

In appetitive situations, overtraining on a brightness discrimination task tends to facilitate reversal learning while increasing the number of perseverative errors and reducing position-responding tendencies during early reversal learning (Mackintosh, 1962; Reid, 1953). In addition, level of motivation has been found to affect reversal learning. Kendler \& Lachman (1958) found that Ss run under $45-\mathrm{h}$ food deprivation during reversal training, took significantly longer to reverse a brightness discrimination than did Ss run under 3-h deprivation. The present study was designed to de termine the effects of amount of training and drive level on reversal learning in an escape situation.

\section{SUBJECTS AND APPARATUS}

Subjects were 36 female albino Holtzman rats, 90-120 days old at the beginning of the experiment. The apparatus was a T-maze, with a start box 12 in. long, a 24 -in. stem, and arms $14 \mathrm{in.} \mathrm{long.} \mathrm{The} \mathrm{height} \mathrm{and} \mathrm{width}$ of the apparatus were 6 in. and 4 in Guillotine doors were manually operated to separate the start box and the arms from the stem. The stem of the apparatus was painted flat grey; one of the arms was black, the other white. The arms could be alternated in order to make position cues irrelevant. The grid floor was electrified by an Applegate Model 250 stimulator connected to a Grason-Stadler grid scrambler.

\section{PROCEDURE}

In the first phase of the experiment, the $18 \mathrm{Ss}$ in the high $(.8 \mathrm{~mA})$ and low shock (. $3 \mathrm{~mA})$ were trained on a black-white discrimination to an 8-out-of-10 performance criterion. The black and white arms of the maze were alternated in a pseudorandom sequence so that each was on the left or right side for three of each block of six trials. After a correct response, which automatically terminated shock, S remained in the correct goal box for $20 \mathrm{sec}$. $S$ was allowed to retrace immediately after an incorrect response. Because of time demands. 16 Ss ( 8 from each shock level), which were responding at chance level after 80 trials, were discarded. The remaining $\mathrm{Ss}$ were then assigned to four groups of five each (high-shock, overtrained; high-shock, immediate reversal; low-shock, overtrained; low-shock, immediate reversal) in such a way that the mean original training scores of all groups were equated. Ss in the reversal groups began reversal training on the day after they reached the 8-out-of- 10 criterion, while overtrained Ss received 95 additional overtraining trials. The shock level was the same in original and reversal training. The reversal criterion was the same as during original training $(8$ out of 10 correct responses).

\section{RESULTS AND DISCUSSION}

Shock level had no effect on number of trials to original training criterion $(t=1.01$, $\mathrm{df}=18$ ). The means for the high- and low-shock groups were 58.4 and 52.6, respectively. An analysis of trials to reversal criterion data indicated no significant effects due to training or shock level, nor was the Shock by Training interaction significant $\quad[F(1,16)<1 ; \quad F(1,16)<1$; $F(1,16)=2.341$. The treatment means were: high-shock, overtrained, 85.80; highshock, reversal, 70.40; low-shock, overtrained, 64.20; low-shock, reversal, 83.80. Analysis of perseverative error data (number of consecutive incorrect choices after cue reversal) indicated a significant effect due to training $[F(1,16)=10.49, p<.01(\bar{X}=7.3$ for overtrained Ss; $\vec{X}=2.3$ for immediatereversal Ss)]. The effects of shock and the Shock by Training interaction were nonsignificant $[F(1,16)<1 ; F(1,16)<1]$.

The tendency to respond positionally during the first 24 reversal trials was also analyzed. A factorial analysis of number of responses to the preferred position indicated a significant training effect $[\mathrm{F}(1.16)=4.80$, $p<.05 \quad(\bar{X}=14.5$ for overtrained Ss: $\mathrm{X}=17.3$ for immediate-reversal Ss) $]$. As in the perseverative error analysis, the effects of shock and the Shock by Training interaction were nonsignificant $[F(1,16)<1 ; F(1,16)<1]$. Further information regarding the tendency to respond positionally was provided by $x^{2}$ analyses computed for each $S$ during the first 24 reversal trials. Six of the reversal $S$ s demonstrated a significant position preference, while only one overtrained $S$ did. While the trials to criterion data are inconclusive, the perseverative error and position response data are in agreement with the results obtained by Mackintosh (1962) and Reid (1953) in appetitive situations. Level of motivation, as induced by electric shock, was an ineffective variable.

REIFRENCES

KENDLER, H. H, \& LACHMAN, R. Habit reversal as a function of shedulc of reinforcement and drive strength. Joumal of Fxperimental Psychology, 1958, 55, 584-591. MACKINTOSH, N. J. The effects of overtraining on a reversal and a nonreversal shift. Journal of Comparative \& Physiological Psychology. $1962,55,555-559$.

RFID, L. S. The development of noncontinuity behuvior through continuity learning. Journal of 1 yperimental Psychology, 1953, 46. 107-112.

$$
\text { NOTE }
$$

1. Now at the University of Scranton, Suranton, Pennsylvania. 